\title{
FORTALECIMIENTO DE LA PARTICIPACIÓN COMUNITARIA A TRAVÉS DE LA RADIO LOCAL. UNA PROPUESTA DE INVESTIGACIÓN-ACCIÓN PARTICIPATIVA (IAP) CON JÓVENES EN CHAITÉN
}

\author{
RODRIGO MARDONES CARRASCOa \& FRANCISCO VELÁSQUEZ TAPIA ${ }^{b}$
}

\begin{abstract}
RESUMEN
En el marco del proyecto "Educación para la integración social de la población afectada por la erupción volcánica de Chaitén", iniciativa emanada desde el Centro de Investigación en Vulnerabilidades y Desastres Socionaturales" (CIVDES), se desarrolló el eje de acción "Talleres de Radio", bajo la metodología de Investigación-Acción-Participativa (IAP) entre los años 2012 y 2013. Éste tuvo como objetivo incorporar la comunicación comunitaria por medio de la radio como instrumento de reconstrucción social en Chaitén, con especial énfasis en el desarrollo de competencias, redes y visibilización de los jóvenes en el medio local. Se implementaron en total 12 sesiones de taller durante la duración del proyecto, con 8 jóvenes entre 14 a 18 años, de la Escuela Juan José Latorre de Chaitén. Esta actividad permitió relevar diversas áreas de interés como fortalecimiento y apoyo comunitario, espacios de socialización y reconocimiento patrimonial natural de una localidad aún en proceso de reconstrucción. Finalmente, se discuten las dimensiones éticas y políticas de la acción comunitaria, la generación de condiciones para hablar de una intervención exitosa, y el lugar del profesional en la dinámica investigativa e interventiva.
\end{abstract}

PALABRAS CLAVE: Desastres Socionaturales, Intervención Comunitaria, Erupción Volcánica, Psicología Comunitaria, Investigación-Acción-Participativa (IAP).

\section{STRENGTHENING COMMUNITY PARTICIPATION THROUGH THE LOCAL RADIO. A PROPOSAL FOR PARTICIPATORY-ACTION-RESEARCH (PAR) WITH YOUNGS IN CHAITÉN.}

\section{ABSTRACT}

In the context of the project "Education for social integration of population affected by the volcanic eruption of Chaitén," an initiative of the Research Center on Vulnerability and Socio-Natural Disasters

a Psicólogo, Universidad de Chile. Becario CONICYT en Magíster en Psicología mención Psicología Comunitaria e Investigador de la Unidad de Estudios Comunitarios Latinoamericanos de la Universidad de Chile. Integrante del Núcleo de Estudios e Intervención Comunitaria (NEICO).rodrigo.mc@ug.uchile.cl

b Periodista, licenciado en Comunicación Social, Universidad Andrés Bello. Magíster en Comunicación Corporativa y Responsabilidad Social Empresarial de la misma Universidad. Docente en Instituto Los Leones y en AIEP. Investigador de la Unidad de Estudios Comunitarios Latinoamericanos de la Universidad de Chile. Integrante del Núcleo de Estudios e Intervención Comunitaria (NEICO) panchojvelasquez@gmail.com 
(CIVDES) the "Radio Workshops" line of action was developed, using Participatory Action Research (PAR) methodology between 2012 and 2013. The objective was to incorporate community communication through radio as an instrument of social reconstruction in Chaitén, with a special emphasis on the development of skills, networking and making youth visible in the local environment. 12 workshop sessions were implemented during the project, with 8 youths aged 14-18 from the Juan José Latorre School of Chaitén. This activity revealed various areas of interest including strengthening and community support, social spaces and the recognition of the natural heritage of a city still under reconstruction. Finally, the ethical and political dimensions of community action, the generation of conditions for a successful intervention, and the place of professional investigative and interventional dynamics are discussed.

KEY WORDS: Socio-Natural Disaster, Community Intervention, Volcanic Eruption, Community Psychology, Participatory Action Research (PAR).

\section{INTRODUCCIÓN}

Chile está constantemente expuesto a desastres socionaturales. El territorio nacional ya ha sido asolado por grandes movimientos telúricos, maremotos, explosiones volcánicas, deslizamientos de tierra, sequías, etc.; situaciones que imponen como un área prioritaria el estudio sobre los efectos de los desastres en la población y la promoción de respuestas que se basen en herramientas y conocimientos compartidos culturalmente.

Esto cobra mayor relevancia debido a los últimos acontecimientos relacionados a desastres socionaturales acaecidos en Chile. Tales como el reciente terremoto que azotó el centro-norte del país el 2015, el movimiento sísmico y posterior tsunami en febrero del 2010 que devastó la zona centro sur del territorio nacional o la erupción volcánica que implicó el desplazamiento total de la población de Chaitén durante el 2008. Estos hechos han demostrado que no estamos preparados para dar respuesta de forma oportuna y organizada ante eventos de tales magnitudes.

La disfunción y la falta de capacidad de los dispositivos tanto institucionales como no gubernamentales para abordar las consecuencias de una catástrofe socionatural agravan mucho más la situación si se trata de sectores vulnerables, tanto geológica como socioeconómicamente (Brzovic et al. 2010). Por ejemplo, producto del terremoto ocurrido en Chile en el 2010 se perdieron 15.000 puestos de trabajo (EERI, 2010), cerca del 3\% de la población chilena cayó bajo la línea de pobreza (Larrañaga \& Herrera, 2010), y más de 200.000 familias perdieron sus hogares (MINVU, 2010). En tanto, en Chaitén, según un estudio realizado por Valenzuela (2012), la calidad de vida de las personas se vio afectada por el miedo constante de vivir expectantes ante un posible segundo episodio volcánico. Además de perder en algunos casos todo lo que poseían, ser evacuados y reubicados en otras localidades, distinta a la que siempre estuvieron acostumbrados.

De acuerdo a lo anterior, una propuesta que contribuya a los procesos de reconstrucción social es la intervención comunitaria (Pérez-Sales, 2002). Para Rodríguez (2009) la acción comunitaria es el modelo más apropiado para responder de forma oportuna y con la participación de los diferentes actores involucrados los procesos de reconstrucción. En Latinoamérica, la psicología comunitaria ha atendido el resquebrajamiento del tejido social, el desamparo e impotencia que viven las personas y comunidades afectadas por desastres (Montero \& Serrano-García, 2011). Resaltando que el cuidado de la salud mental y el bienestar psicosocial necesita de la participación de las comunidades y sus líderes (Rivera et al. 2014).

Bajo estos supuestos nace el proyecto "Educación para la integración social de la población afectada por la erupción volcánica de Chaitén", conformado por académicos, estudiantes y funcionarios de la Facultad de Ciencias Sociales, Facultad de Artes y la Facultad de Arquitectura y Urbanismo de la Universidad de Chile (Velásquez, 2012, 30 de marzo). Este proyecto, financiado por la Vicerrectoría de Extensión de aquella casa de estudios, buscaba implementar una estrategia interdisciplinaria con el fin de construir intervenciones bajo un sustrato teórico pertinente a la especificidad de los impactos psicosociales de erupciones volcánicas. 


\section{CONTEXTO Y DESAFÍOS PARA LA RECONSTRUCCIÓN EN CHAITÉN}

La erupción del volcán Chaitén en 2008 se inició con una serie de temblores culminando el 2 de mayo con una gran explosión (Castro \& Dingwell, 2009; Lara 2009; Mardones et al. 2011) lo que obligó a las autoridades a declarar "Estado de Catástrofe" e iniciar un proceso de evacuación voluntaria de la población. Es así como en menos de 48 horas se traslada a aprox. 3.900 chaiteninos a albergues de ciudades aledañas (El País, 2008, 03 de mayo). Sin embargo, durante los días siguientes, la actividad eruptiva registró un aumento continuo, por lo que se ordena la evacuación total de la población a pesar de la resistencia de algunas familias (Espinoza, 2013; Gutiérrez, 2008, 08 de mayo; Lara, 2009). Mientras que el gobierno desplegaba una serie de ayudas económicas y sociales para fomentar los procesos de reubicación de la gente (Mardones et al. 2011).

Diez días más tarde, el desprendimiento de parte del domo del volcán ocasionó el desborde del Río Blanco atravesando y dividiendo a Chaitén a la mitad: el sector norte y el sector sur, causando la inundación del $90 \%$ del lugar y la destrucción de 219 casas las que fueron arrastradas hacia el mar (Lara, 2009; Mardones et al., 2011).

Un informe realizado por el Ministerio de Obras Públicas [MOP] el 05 de agosto del 2008 señala que la pérdida de la edificación pública luego de la erupción y posterior aluvión dejó sepultada gran parte de Chaitén bajo las cenizas arrojadas por el volcán. Varios edificios públicos sufrieron daños, dejando dos de los tres colegios del sector inutilizables (Osorio, 2008). Además, el 04 de agosto de 2010 la localidad de Chaitén sufrió un incendio devastador destruyendo importantes edificios fiscales, como la Gobernación Provincial, la Municipalidad y la Oficina de Correos.

En este escenario de profunda incertidumbre sobre la evolución futura de la actividad volcánica y la presión de los chaiteninos por regresar a sus hogares, las autoridades, en el 2010 anunciaron la reconstrucción de Chaitén en el sector norte de la ciudad (EMOL, 2011, 9 de abril).
A partir de aquella fecha, la cantidad de personas que han retornado ha aumentado considerablemente año tras año (González, 2011). Se han habilitado los servicios básicos de luz, agua, telecomunicaciones, educación y salud en la parte norte de la ciudad (Espinoza, 2013; González, 2011). Sin embargo, existen alrededor de 200 familias que residen en Chaitén Sur (Fernández, 2012, 19 de mayo), una zona aún cubierta de cenizas y declarada "inhabitable". Este sector tiene un acceso restringido a luz y agua, no cuenta con una escuela y presentan grandes dificultades de conectividad (Alfaro et al. 2010; Macaya, 2012).

Tal como expone Jiménez (2012) el desastre en Chaitén subrayó el aislamiento de la zona. En este contexto, uno de los medios de comunicación más usados, es la radio. Es uno de los pocos canales de conexión entre la misma comuna y entre otras comunas de la región. A través de este medio se dan a conocer las noticias del acontecer nacional, así como local. Un ejemplo de esta cultura radial lo constituye el hecho de que Bernardo Riquelme, dueño y locutor de la Radio Chaitén, decidiera quedarse en el pueblo con posterioridad a la erupción transmitiendo diariamente hasta que fue evacuado por la fuerza (Gutiérrez, 2008, 08 de mayo). Su programa era la conexión entre la ciudad y los chaiteninos desplazados, quienes lo llamaban para saber si había temblado o para pedirle que visitara y constatara el estado de sus casas (Ramírez, 2008, 01 de agosto).

Estas acciones reflejan la importancia de la comunicación radial, ya que a nivel local representa un aporte esencial en los procesos de desarrollo, además juega un rol importante en la democratización, en las reivindicaciones sociales y en la generación de conocimientos, caracterizándose por sualto grado de horizontalidad, apertura y posibilidades de participación (Milan, 2006; Rebolledo, 2011).

Es así como el proyecto "Educación para la integración social de la población afectada por la erupción volcánica en Chaitén" llevado a cabo entre los años 2012 y 2013, dependiente del Centro de Investigación en Vulnerabilidades y Desastres Socionaturales (CIVDES) de la Universidad de Chile, buscaba abordar la problemática de la desintegración 
social derivada del desplazamiento forzado de toda la localidad, con especial atención en la promoción de herramientas que permitieran consolidar una comunidad más resistente física, psicológica y socialmente ante futuras amenazas socionaturales. Para ello, se propuso el diseño y la implementación de un programa educativoparticipativo con las comunidades escolares de tres establecimientos educacionales: Pillanlikan en Puerto Montt (establecimiento construido por chaiteninos desplazados), Juan José Latorre en Chaitén (única escuela en función en el sector) y la Escuela Unidocente de Chana (ubicada en la zona rural de la comuna de Chaitén).

Este artículo profundizará en una de las actividades realizadas en la Escuela Juan José Latorre de Chaitén, el eje de acción "Talleres de Radio". Se dará cuenta de esta experiencia de Investigación-Acción-Participativa (IAP en adelante), realizada por medio de talleres de capacitación radial para jóvenes de 14 a 18 años, que tenía por objetivo producir contenidos que resaltaran historias reales y sentidas de cada día, destacando las miradas de los jóvenes, otorgando protagonismo a sus voces y fortaleciendo su participación.

\section{REPENSANDO EL DESASTRE: LA NECESIDAD DE UN CAMBIO PARADIGMÁTICO}

Una necesidad imperante es revisar el concepto de desastres desde el cual se abordan diversas intervenciones psicosociales. La definición más difundida y aceptada, es aquella proveniente de las "ciencias duras" tradicionales, que exponen que para que se produzca un desastre debe existir una cuantificación posible de las consecuencias en la zona de impacto de una amenaza (Cardona, 2001; Gellert, 2012; Lavell, 1997).

Un ejemplo de lo anterior, es que para la Organización Panamericana de la Salud (OPS) un desastre consiste en un acto de la naturaleza cuya magnitud da origen a una situación catastrófica. En ella, se alteran de forma repentina los patrones cotidianos de la vida y la gente se ve hundida en el desamparo y el sufrimiento, generando como resultado la necesidad de asistencia y entrega de elementos fundamentales para la vida, los cuales, en la mayor parte de los casos, deben provenir de áreas que estén fuera del desastre (Villalobos, 2009).

Sin embargo, este tipo de definiciones no son capaces de abordar la compleja construcción de los desastres en sociedad, pasando por alto el campo de tensiones políticas, sociales, culturales, históricas y ambientales que los producen. Además, suelen resaltar la necesidad de ayuda externa para las comunidades afectadas, con el fin de alcanzar nuevamente un estado de funcionamiento normal, lo que deja a los protagonistas del desastre en una posición de desamparo e inacción (Berríos, 2009; Cardona, 2001).

En efecto, las condiciones económicas, la falta de empleo, la precariedad de los servicios y los problemas de conectividad, especialmente en sectores rurales, producen localidades altamente vulnerables. Por lo mismo, resulta fundamental focalizar el análisis a nivel local, donde el riesgo se expresa de forma concreta, facilitando la vinculación de la gestión del riesgo a los proyectos de desarrollo local o comunitario (Coloma, 2009).

Por ello, se consideran los desastres socionaturales como:

Una producción social en torno a la manifestación de fenómenos naturales permanentes o coyunturales que adquieren un carácter de amenaza en contextos de vulnerabilidad, como resultado de diversos conflictos políticos, económicos, ambientales, sociales y culturales, provocando una desorganización y ruptura del tejido social, histórica y geográficamente definida (Mardones, 2014, p. 31).

Esta manera de definir los desastres no se centra en el daño material y/o la pérdida de vidas humanas, ni tampoco en la necesidad de ayuda externa para que las personas o comunidades puedan salir adelante, sino que apela a la reorganización comunitaria, cambiando el foco de la reflexión hacia la caracterización de las personas como agentes activos y a la realización de acciones prospectivas en torno a la superación de vulnerabilidades sociales, congruentes con 
un enfoque comunitario en el abordaje de los desastres socionaturales (Pérez-Sales, 2004).

\section{EL LUGAR DE LAS JUVENTUDES EN LOS PROCESOS DE RECONSTRUCCIÓN}

Según Pérez-Sales (2004), existen tres dimensiones claves para la reconstrucción: la sensación de pertenencia, el clima social y el control sobre la propia vida. La primera refuerza el sentido de comunidad y la construcción de narrativas colectivas, mientras que el clima social positivo permite visibilizar y reconocer el sufrimiento sin temor al rechazo. Finalmente, el control sobre la propia vida afirma la autoeficacia y la autodeterminación para un desarrollo futuro independiente (Rivera et al. 2014).

Sin embargo, en contextos post-desastre existe una alta propensión a la vulneración de derechos, especialmente de los jóvenes. Por ejemplo, entre los efectos más frecuentes se observa la propensión a afecciones en la salud física, una disminución general de la calidad de vida: acceso a la atención en salud, alimentación, vivienda, y educación. A su vez, pueden incrementarse los niveles de pobreza y vulnerabilidad de estos grupos, debilitar o romper las redes de apoyo, y provocar la separación o desintegración de la familia (Instituto Interamericano del Niño, Niña y Adolescente [IINA], 2011).

Espinoza (2013) documenta en su investigación que el proceso de evacuación en Chaitén, caracterizado por sufalta de planificación, implicó la división de familias completas quienes ante la contingencia de abandonar el sector y la prioridad de la salida de mujeres y niñas/os, fueron ubicadas en distintos transbordadores desconociendo el lugar de destino (Espinoza, 2013).

Por ello, es necesario reconocer las necesidades de jóvenes en situaciones de catástrofes, y no profundizar y perpetuar brechas $e$ inequidades existentes previamente (Brennan, 2008; IINA, 2011; Todres, 2011). Por lo tanto, si se implementaran estrategias y recursos adecuados, dirigidos hacia el fortalecimiento de mecanismos de participación de adolescentes, significaría, entre otras cosas, potenciar sus capacidades locales en situaciones de nuevas catástrofes (IINA, 2011).
De esta manera, se contribuye por un lado, al desarrollo de sociedades más democráticas, justas e inclusivas, y por otro, habilita respuestas más efectivas, estimulando encuentros intergeneracionales y renovando el rol de los jóvenes, posicionándolos como agentes de cambio (IINA, 2011).

\section{LA PROPUESTA DE INTERVENCIÓN RADIAL: APORTES DESDE LA INVESTIGACIÓN- ACCIÓN-PARTICIPATIVA (IAP)}

El desarrollo del proyecto "Talleres de Radio" se basó en la premisa de que las estrategias de intervención permiten producir información en las diferentes etapas del proceso, la que es validada desde la comunidad, sustentando asî nuevas propuestas interventivas basadas en nuevos diagnósticos de necesidades y expectativas, coconstruyendo operaciones reflexivas y dialógicas donde intervención e investigación se nutren constantemente (Mardones, 2014).

Lo anterior constituye el núcleo de la IAP, la que es entendida como una metodología para diagnosticar, intervenir y evaluar los procesos psicosociales considerados injustos o problemáticos, tanto por los investigadores como por los participantes de las comunidades, transformando la teoría en práctica y la práctica en teoría, movilizando una conciencia crítica y transformadora de nuestra realidad social (Krause, 2002; Montero, 2006).

La IAP no es propiedad de una disciplina en particular, más bien, es un punto convergente en la forma de hacer investigación (Brydon-Miller et al., 2003). Por ejemplo, es posible observar incipientes elementos de la investigación-acción en las obras de John Dewey, relacionados a sus estudios en educación (Brydon-Miller et al. 2003), o en las investigaciones de Kurt Lewin (Flores, 2011) vinculadas al ámbito laboral en los EE.UU. en la década del 40 . Por otra parte, el surgimiento de voces y propuestas críticas dentro de las ciencias sociales latinoamericanas en los años '60, se sumó a la insatisfacción con los modos de hacer ciencia, al conocimiento generado y a su capacidad de explicación y transformación de la sociedad (AnderEgg, 2003; Montero, 2004). Esto determinó la emergencia de esta alternativa epistemológica y 
metodológica que tenía por finalidad contribuir con la construcción de prácticas de transformación social (Freytes \& Cross, 2011; Ortiz \& Borja, 2008; Vázquez, 2005).

Los antecedentes y orígenes de la IAP se remiten al ámbito de la educación, difundidos a través de la obra de Paulo Freire; y al ámbito de la sociología en su vertiente militante, expresada en primer lugar en la obra de Fals-Borda (Ahumada et al. 2012). En Latinoamérica, la psicología comunitaria ha incluido esta contribución metodológica, abocándose a temáticas psicosociales y sociopolíticas en comunidades con características de marginación, exclusión y opresión (Ahumada et al. 2012).

Según Fals-Borda (1985) los principales objetivos de la IAP son: (a) el proceso colectivo de investigar temas sociales para producir conocimiento; (b) la recuperación crítica de la historia; (c) el uso y la validación de la cultura popular, y (d) la devolución y difusión de conocimiento nuevo. Estas características hacen de la IAP una estrategia adecuada dada su capacidad de producir transformaciones a través de la acción conjunta entre agentes externos e internos.

Esta metodología de investigación resulta coherente con el fin de visibilizar las experiencias y perspectivas de los grupos, cuyas vivencias y voces no son consideradas a nivel comunitario (Freytas \& Cross, 2011). En este sentido, la radio local, permite contribuir al desarrollo de dos campos fundamentales (Milan, 2006):

a) En el nivel procesal, como un canal de participación. Los medios comunitarios representan "la voz de los sin voz" y permiten a las personas $y$, especialmente, a las comunidades marginadas expresar sus preocupaciones. Específicamente, la radio local contribuye a satisfacer las necesidades y el desarrollo de la comunidad, promoviendo el cambio social y la democratización de la comunicación a través de la participación comunitaria (Beneton, 2006).

b) En el nivel simbólico, como un medio de toma de poder. Al dar a la gente la capacidad de generar iniciativas en escala local, muestra que el cambio es posible. Representa un modo de ejercicio de la imaginación y de su transformación en prácticas situadas. La comunidad crea significados compartidos e interpretaciones de la realidad, vislumbrando al mismo tiempo oportunidades de cambio (Milan, 2006).

Por ello, esta estrategia de intervención brinda la oportunidad de relevar y construir conocimientos de aquellos aprendizajes significativos en el área de los desastres socionaturales, donde se ha promovido que los jóvenes se conviertan en o-constructores del sentido de la experiencia del riesgo y de los procesos de desplazamiento y retorno vividos.

\section{PARTICIPACIÓN, FORTALECIMIENTO Y PATRIMONIO COMUNITARIO.}

De acuerdo a lo mencionado anteriormente, la radio comunitaria es un medio que nos permite ahondar en dos niveles difíciles de abordar por otras herramientas al servicio de la intervención comunitaria: el nivel procesal y el nivel simbólico, es decir, las dimensiones de la participación y el fortalecimiento comunitario respectivamente.

La participación, en primer lugar, comprende un proceso de concientización colectiva, desde las comunidades, acerca de los factores que potenciarían o disminuirían sus conocimientos y desarrollo. La reflexión crítica sería el medio de confluencia de esta acción, la cual desencadenaría procesos de organización y asociatividad orientadas a un logro o bien en común (Montero, 2010a). En palabras de Montero (2004, p. 229), la participación comunitaria se define entonces como "un proceso organizado, colectivo, libre, incluyente, en el cual hay una variedad de actores, de actividades y de grados de compromiso, que están orientados por valores y objetivos compartidos, en cuya consecución se producen transformaciones comunitarias e individuales".

Otra dimensión abordada por medio de la radio comunitaria es la simbólica. Con esto nos referimos a la compleja temática del poder y el fortalecimiento de las comunidades. La preocupación por las propuestas de investigación y acción respecto de las manifestaciones del poder, es un tema en constante debate. En este sentido, una de las primeras aproximaciones al fenómeno del poder en las comunidades se 
contiene en el concepto de "empoderamiento" o "empowerment”, acuñado por Rappaport (1981 en Musitu \& Buelga, 2004, p. 103), quien lo define como "el proceso por el cual, las personas, organizaciones y comunidades adquieren control y dominio de sus vidas". Es decir, es la facultad en el que las personas de una comunidad adquieren la capacidad para poder administrar y tratar de solucionar las problemáticas que los aquejan (Ansaldo \& Lara, 2009).

En este sentido, el concepto de empoderamiento es capaz de abordar los procesos internos en el que las poblaciones generan acciones y actividades de forma conjunta $y$ autónoma para intervenir sobre sus vidas (Ansaldo \& Lara, 2009). Sin embargo, este concepto no está exento de críticas. Vázquez (2004, p. 50) acusa un abuso del uso del término empowerment o empoderamiento, argumentando que no se han considerado sus limitaciones, tales como "su tendencia a lo individual, su afinidad con el poder como posesión y sus raíces culturales".

Ante este tipo de críticas, Maritza Montero (2010b) propone el término "fortalecimiento", considerando una visión dinámica y dialéctica del poder, suponiendo que puede ejercer su influencia tanto desde fuera de la comunidad y hacia ella, como ser producida dentro de la misma comunidad (Montero, 2010b). Podemos definir fortalecimiento como "el proceso mediante el cual los miembros de una comunidad (individuos interesados $y$ grupos organizados) desarrollan conjuntamente capacidades y recursos para controlar su situación de vida, actuando de manera comprometida, consciente y crítica, para lograr la transformación de su entorno según sus necesidades y aspiraciones, transformándose al mismo tiempo a sí mismos" (Montero, 2009, p. 616).

Así, fortalecer una comunidad no significa que un agente externo interviene para brindarle fuerza a personas desvalidas, miembros de una determinada comunidad, sino que es un proceso que realizan las comunidades para desarrollar y potenciar crítica y reflexivamente sus capacidades y recursos (Musitu \& Buelga, 2004).

En la búsqueda de caminos posibles, se ha llegado a la convicción de que las modalidades de trabajo comunitario, que puedan implicar una verdadera transformación de las condiciones de desarrollo local, se relacionan con el logro de hacer del territorio un espacio de cambio y crecimiento para todos los actores involucrados en el desafío de construir acciones en favor de la disminución de las vulnerabilidades (Mardones, 2014).

Adentrándonos en la especificidad de la localidad donde se llevó a cabo la propuesta de IAP, para los casi mil chaiteninos retornados, este proceso no sólo ha implicado el redescubrimiento de nuevos modos de relacionarse entre ellos, sino que también con el paisaje y el territorio (Jiménez, 2012). Por ello, es necesario plantear una actitud ética frente al ambiente, su construcción y cuidado, y no considerar únicamente al ser humano como simple espectador o contemplador pasivo, sino también participativo y responsable de sus actuaciones (Gómez, 2010).

La noción de territorio es más compleja en cuanto al papel que éste desarrolla en la construcción de los vínculos de una comunidad. Esta ya no sólo se define sobre la base de la proximidad ni se crea por reparto pasivo de un cierto espacio y de su valor simbólico, sino que deriva de la actuación colectiva de los agentes portadores de prácticas y conocimientos productores del territorio y de una nueva lógica de referencia identitaria de los lugares (Quiroz, 2006). Tal como lo señala Quiroz (2006), el territorio es interpretado como un desafío, una oportunidad, una construcción. Los contextos físicos y la comunidad local, se definen a partir de la multiplicidad de las prácticas y de los roles sociales y culturales de los agentes.

Bajo estos parámetros, el patrimonio "natural", a la vez construido en sus relaciones y significados, corresponde a un patrimonio vivo que tiene la posibilidad de recrearse y reinterpretarse continuamente en el tiempo. Esta construcción requiere ser reconocida de forma simbólica por los usos de la comunidad donde se forja. El territorio tiene vida en la comunidad, siendo parte de las formas de expresión de su propio patrimonio.

Para lograr un acercamiento ético en la interpretación del territorio, se propone una metodología de análisis que ofrezca herramientas de diseño para intervenciones locales, que se puedan transformar en alternativas de actuación y como estrategia de mitigación de vulnerabilidades ante posibles nuevos desastres (Gómez, 2010). 


\section{LOS MOMENTOS DE LA INTERVENCIÓN}

La intervención se plantea en cuatro momentos, definidos por Rivera et al. (2014), los cuales muestran el protagonismo ascendente de la comunidad, donde en cada fase se observan objetivos conectados al análisis de la problemáticas psicosociales y las estrategias de intervención comunitaria.

\section{Conformación del grupo y sensibilización}

La intervención comunitaria se inició debido a la demanda explícita del director de la Escuela Juan José Latorre, preocupado por la violencia de alumnos y alumnas retornadas a Chaitén. Por ello, comenzamos con un diagnóstico comunitario, entendido como una construcción que intenta dar cuenta de los sentidos, significados y problemáticas priorizadas por los diferentes miembros de una comunidad (Ulivarri, 2010), considerando como relevante las aproximaciones al conocimiento de sus formas de vivir, los recursos comunitarios con los que cuentan y la lectura de la realidad que construyen (Ulivarri, 2010).

Así, las primerasaproximacionesala situación ocurrida en Chaitén se fueron construyendo a partir de la información recopilada por medio de fuentes secundarias (revisión de documentos y noticias y entrevistas a informantes claves), realizando una identificación preliminar de las características sociodemográficas, socioculturales e históricas de la comuna. Esto implicaba una revisión tanto de antecedentes socio-históricos o estadísticopoblacionales, como también de las disposiciones jurídico-legales, las estructuras institucionales, sus funciones y relaciones en el entramado social de la comunidad, las cuales finalmente regularon las acciones del Estado frente a la situación de catástrofe.

Luego, se abordó la definición del grupo objetivo con el cual se iba a trabajar, en este caso los jóvenes de la escuela, con quienes se elaboró el diseño de una estrategia de diagnóstico participativo en conjunto, lo que permitió generar un dispositivo lo menos intrusivo posible. Se decidió realizar 1 taller con cada curso del establecimiento, en el cual realizamos dibujos ( $1^{\circ}$ básico a $4^{\circ}$ básico), collages con diversas imágenes de revistas $\left(5^{\circ}\right.$ básico a $8^{\circ}$ básico) y microcuentos $\left(1^{\circ}\right.$ medio a $4^{\circ}$ medio) bajo la sencilla consigna ¿Cómo me siento hoy en Chaitén? Esto permitió indagar en las demandas y necesidades de los jóvenes, visualizando la pertinencia y viabilidad de este proceso de IAP. Por último, se realizaron entrevistas diagnósticas breves a jóvenes de enseñanza media. Los resultados destacaron la importancia de la comunicación radial en la localidad y los nulos espacios para la participación de jóvenes en su comunidad en los cuales puedan comunicar sus demandas $y$ necesidades.

“(...) cuando pasó la erupción, fue la primera vez que supieron de Chaitén. Fue como que ahí se resaltó Chaitén y ahora como que quedó en el pasado. Pero la radio nos ha apoyado harto y como que está representado a toda la gente, a toda la comunidad de Chaitén" (Entrevistado, 16 años, 2013).

"Como que la gente está en su casa, encerrada en su computador. Yo encuentro que eso falta ahora, como lugares de reunión, así sociales" (Entrevistada, 16 años, 2013).

"Esa educación (referido a temas como sexualidad y drogas) se te da en la casa o se te da en el colegio, pero no se da en ninguna de las dos" (Entrevistado, 15 años. 2013).

En síntesis, la pertinencia del taller radial se encuentra dada por el fácil acceso a aparatos radiales en la zona y la importancia de este medio en territorios rurales caracterizados por su aislamiento geográfico. Así mismo, la generación de espacios de intercambio social para jóvenes de la localidad.

\section{Participación para la acción}

Constituido el núcleo central a cargo de los talleres de radio (un psicólogo y un periodista), fue posible identificar que la coordinación entre un equipo reducido $y$ heterogéneo enriquece el intercambio de perspectivas y experiencias. Los objetivos para la actividad que se plantearon fueron:

a) Conocer y reconocer estructuras básicas para la entrega de información.

b) Elaborar textos radiales en base a recursos como el guion y libreto. 
c)

Elaborar recursos de apoyo que den dinamismo a la locución como son: cápsulas, vox pop, entrevistas, incorporación de sonidos de apoyo y elementos que enriquezcan el texto informativo.

d) Nociones básicas para la realización de edición de programas radiales.

Una vez identificados, delimitados $y$ conceptualizados los objetivos de la investigaciónacción, se comenzó el proceso de diseño de la intervención. En este punto, la participación de los agentes comunitarios fue fundamental, ya que así el diseño adquiere mayor validez y pertinencia práctica (Montero, 2006, 2009). Se identificó y trabajó junto al director de la escuela Juan José Latorre de Chaitén y el director de la Radio Chaitén, como aliados comunitarios estratégicos, quienes brindaron su apoyo inmediato, abriendo la posibilidad de que el resultado de los talleres de radio, un programa piloto, pudiera ser transmitido por la radio local.

La estrategia para la seleccionar a los participantes, fue la elección democrática de 3 jóvenes por cada curso comprendido entre $7^{\circ}$ de enseñanza básica y $2^{\circ}$ de enseñanza media, por parte de los mismos alumnos/as en conjunto con su profesor jefe. El perfil no consideraba un historial de calificaciones destacadas, sino más bien, la alta motivación y disposición comprometida de ser parte de la actividad. Además, se invitó integramente al Centro de Alumnos de la escuela, con el fin de otorgar herramientas para los fines de esta organización escolar.

Se proyectaron 3 visitas a terreno de una semana de duración. La planificación para cada una de las 3 tandas de talleres, incluyó la realización de 4 sesiones. En el primer taller se discuten temáticas introductorias como la construcción de notas y creación de pautas periodísticas. La segunda sesión se destinará a la profundización de géneros periodísticos como lo son la entrevista, opinión y notas informativas. La tercera sesión se abocaría a la creación de un guion radiofónico con contenidos propuestos por los mismos jóvenes y la realización de entrevistas en terreno. Para la sesión final se llevaría a cabo la grabación de un programa de 20 minutos por parte de los conductores, comentaristas y periodistas juveniles.

\section{Movilización comunitaria}

En esta fase se puso en marcha toda la estructura definida previamente, por medio de la implementación de sesiones de taller participativos. La modalidad de taller, según Londoño y Atehortúa (2011), actúa como un espacio integrador que permite compartir, hablar, recrear y analizar diversos elementos, relaciones y saberes, proveyendo el (re)conocimiento social entre los sujetos. En este sentido, fue muy valorado por parte de los jóvenes la inclusión de actividades y dinámicas lúdicas que promovían la adquisición de nuevos aprendizajes y el desarrollo de habilidades relacionales y comunicativas.

Se contó con la participación activa y sostenida de 8 alumnos del establecimiento entre 12 y 17 años.

"(El taller)... estuvo genial. Así como que hasta daba ánimo de venir, hasta con la intensidad de la voz con las que decían las cosas. Como que uno al final está aprendiendo pero de una manera distinta de aprender donde te dan ánimo..." (Entrevistada, 14 años, 2013).

Durante este proceso, se realizaron capacitaciones en géneros periodísticos tales como la crónica, reportaje, opinión y entrevistas. Además, las tandas de talleres, incluían diversos juegos y dinámicas grupales con el fin de generar un ambiente lúdico y confiable.

Así mismo, es invitado a la sesión inaugural, el locutor de la Radio Chaitén, quien relató su experiencia en radio, lo que significó vivir el desplazamiento forzado luego de la erupción volcánica y el retorno a la ciudad. Durante los talleres los jóvenes participaron en actividades, tanto teóricas como prácticas, enfatizando la importancia en el aprendizaje de contenidos básicos y su posterior concreción con ejercicios de análisis y recreación de noticias locales. También se incluían ejercicios de articulación, proyección vocal y respiratoria.

Cabe destacar, que un tema transversal en la producción de los programas radiales, fue la reconstrucción de Chaitén, enfatizando el "Chaitén actual" y no el "Chaitén del volcán" como ellos mismos lo denominan. 
Cada sesión de cierre de la intervención se generaba una conversación entre facilitadores y jóvenes acerca de sus apreciaciones, la evaluación del taller, motivaciones y expectativas de futuro.

\section{Fortalecimiento comunitario}

Finalmente, el programa radial "La Otra Mirada Chaitén" (como fue bautizado por los propios jóvenes), se consolidó como el producto final de este proceso, consiguiendo una franja horaria fija y estable en la programación de la radio local, convirtiéndose en una tribuna de opinión sobre diversos temas relevantes para los jóvenes de Chaitén. De hecho, el trabajo radial sostuvo como posibilidad la potenciación y fortalecimiento de la imagen de Chaitén y de los jóvenes como agentes constructores de aquellos sentidos. Los jóvenes enfocaron los contenidos en la entrega de información útil de carácter local, así como de relevar aspectos turísticos, proyectando los avances en torno a la reconstrucción de Chaitén.

"Llegas acá teniendo internet, diciéndole a una persona de afuera, diciéndole sabes acá también hay espacios, hay jóvenes que quieren dar su opinión, por eso en estos momentos estoy trabajando en la radio o también dando a conocer mis ideales, los temas que a mí me interesan, temas que a los jóvenes les interesan como es la música, el arte, cosas que de repente acá no se tratan mucho" (Entrevistada 16 años, 2013).

"(...) desde Chaitén podemos contar que sí hay gente, que sí hay cosas, que aquí si se pueden hacer cosas, que hay una ciudad, que hay supermercados, que hay hoteles. Entonces de alguna manera, también se va entregando un mensaje que no es necesario irlo diciendo uno por uno sino que masivamente" (Director de la Radio Chaitén, 2013).

De esta forma, la promoción de la comunicación a nivel local se concibe como una herramienta útil en el campo comunitario, donde se pone en juego la visibilización, participación $y$ fortalecimiento de grupos generalmente marginados o excluidos.

\section{DISCUSIÓN}

El taller de radio realizado con jóvenes en el contexto del proyecto "Educación para la integración social de la población afectada por la erupción volcánica de Chaitén", dio cuenta de la necesidad de expresión que los estudiantes de la Escuela Juan José Latorre tenían respecto a comunicar su forma de percibir, no sólo lo que había sido el desplazamiento vivido luego de la erupción, sino que la manera en que Chaitén se ha reconstruido con nuevas dinámicas de vida.

Por lo mismo, los estudiantes denominaros su programa "La Otra Mirada", una mirada que no tiene una función comercial ligada a la fabricación de consenso (Feo \& Feo, 2013), sino más bien, trabajar desde un discurso propio la contingencia nacional y local.

En términos concretos, a partir del diagnóstico comunitario realizado fue posible disponer de información preliminar para contextualizar el trabajo a realizar en la localidad, instalando un hito para el inicio de la IAP. El diagnóstico como entrada y familiarización del equipo interventor con los sujetos partícipes de la propuesta, se sumerge en una doble dirección, en tanto cuestiona y obliga a la revisión profunda y participativa de los problemas y necesidades que aquejan a los jóvenes de la localidad. Es así, como el reconocimiento de las fuentes secundarias, como de los procesos de construcción de información por medio de dispositivos tanto grupales como individuales, se transforman en una guía para pensar el desarrollo de la IAP.

En otro ámbito, los procesos de diseño y planificación de intervenciones, reviste un proceso complejo de consolidación de un equipo de trabajo, no tan sólo al interior del grupo interventor, sino que también proyectando la participación de agentes internos como aliados estratégicos.

Además, el uso de dinámicas interactivas y el desarrollo de actividades participativas, en un contexto de confianza y respeto por parte de los agentes externos, permitió procesos de capacitación no tan sólo en herramientas comunicacionales, sino que también de liderazgos comunitarios. Se generaron semilleros de participación, capacitando 
a los propios sujetos para liderar procesos de transformación en sus comunidades.

Esta intervención permite identificar algunos principios centrales, que se mostraron eficaces en contextos post-desastre. Ellos son:

a) El cuestionamiento de las nociones tradicionales respecto a la intervención en desastres socionaturales;

b) La importancia de las experiencias y conocimientos locales para el desarrollo pertinente de cualquier intervención a nivel comunitario;

c) La relevancia de promover estrategias locales y participativas para el abordaje de problemáticas a nivel comunitario, con especial atención a la pertinencia sociocultural;

d) La incorporación de la dimensión afectiva en el trabajo comunitario con los/las participantes y la comunidad, como espacio para la diferencia, la confianza, el afecto y el diálogo; y

e) Reconocer la necesidad de la coordinación con diversas instituciones validadas localmente para potenciar los recursos $y$ posibilitar cubrir diferentes demandas.

Finalmente, se aprecia la relevancia de las acciones territoriales como focos de coconstrucción de saberes, visibilizando el trabajo realizado, sustentando la producción académica en contextos concretos y transformando las situaciones iniciales en las que los profesionales comunitarios toman parte.

\section{CONCLUSIONES}

Uno de los grandes aportes de las ciencias sociales frente a los desastres socionaturales, es impedir que los fenómenos naturales en sí se transformen en un sinónimo de catástrofes. Un desastre "natural" resulta de las confluencias de diversos factores como el deterioro ambiental, la carencia de una educación en gestión del riesgo, una falta de organización estatal y de los modelos socioeconómicos imperantes que dejan vulnerables innumerables localidades.

Hasta la fecha, los factores sociales que inciden en la construcción social de riesgos han sido escasamente explorados y se privilegian aquellas investigaciones correspondientes a las ciencias naturales tradicionales. El dominio que éstas ejercen sobre la comprensión de esta problemática en nuestro continente es casi total. El estudio de patrones sísmicos y climatológicos, de la dinámica terrestre y de estructuras ingenieriles entre otros variados aspectos, grafica el énfasis notorio en la necesidad de predicción de los fenómenos naturales y de la importancia de la adecuación de las estructuras físicas ante desastres.

Sumado a lo anterior, el alto grado de centralismo en el diseño e implementación de políticas públicas, incluso en el ámbito regional, plantea el desafío de generar una adecuada articulación con los órganos locales para facilitar y apoyar el trabajo de los municipios y organizaciones a nivel comunitario.

En general, las dificultades mencionadas con anterioridad, son más bien el reflejo de la gran distancia existente entre una cultura de planificación y gestión local, y la realidad actual de la gran mayoría de las instituciones estatales. Las cuales se movilizan en torno a modelos tradicionales de acción preferentemente asistencialistas, sectoriales y de carácter reactivo.

Dado lo anterior, resulta necesario valorar las actividades construidas a partir de propuestas territoriales. La presencia o no de esta modalidad de trabajo, puede implicar una gran diferencia entre una acción comunitaria rígida y tradicional, y el logro de una intervención abierta y flexible, que sea capaz de hacer del territorio un espacio de desarrollo y crecimiento para todos los actores involucrados. Mucho más si se trata de jóvenes, quienes han sido relegados a una concepción pasiva y asistencialista, dando por hecho su incapacidad de crear y transformar su realidad.

Este trabajo, permite comprender la importancia de la congruencia entre las necesidades de las comunidades y la proposición de soluciones planificadas, que efectivamente se encaminen en torno al desarrollo comunitario y al fortalecimiento social. En ese sentido, uno de los logros más interesantes del proyecto fue la facilitación de procesos de movilización de los propios recursos de la comunidad (Ander-Egg, 2003; Montero, 
2006; Rivera et al. 2014). La implementación de estrategias creativas permitió constituir espacios de encuentro con otros sobre las experiencias y expectativas propias en relación a la reconstrucción de Chaitén.

De esta forma, se concluye que la reducción de vulnerabilidades en contextos de post-reconstrucción, luego de devastadores desastres socionaturales, no puede realizarse de manera eficaz y sustentable sin el consenso de la comunidad, es decir, sin un proceso participativo. Es por ello que se considera a la IAP como una de las metodologías más adecuadas y eficaces para lograr cambios significativos en esta materia.

Por último, es importante, realzar la capacidad de articulación entre diversos actores de la comunidad, teniendo en cuenta una visión integral de la vulnerabilidad de un territorio y de su población. Dicho en otras palabras, el tema de la reconstrucción post-desastres socionaturales no debe enfocarse tan sólo en los aspectos físicos y técnicos de la vulnerabilidad, sino que también en las dimensiones sociales y relacionales.

\section{REFERENCIAS}

Ahumada, M., Antón, B., \& Peccinetti, M. (2012). El desarrollo de la investigación acción participativa en psicología. Revista Enfoques, 24(2), 23-52.

Alfaro, V.; Chahuán, C., \& Reyes, C. (2010). Chaitén: La comunidad fantasma de la Carretera Austral. Recuperado de http:// observatoriodecatastrofesydesastresnaturales.files. wordpress.com/2010/12/chaiten.pdf

Ander-Egg, E. (2003). Repensando la Investigación-Acción Participativa. Buenos Aires: Lumen Humanitas.

Ansaldo, M., \& Lara, V. (2009). Una aproximación a formas de comunicación alternativa: Radios Comunitarias $y$ empoderamiento social de los vecinos: tres estudios de caso. (Tesis de titulación inédita). Pontificia Universidad Católica de Chile: Chile.

Argandoña, C. (2012). Definen zonas de riesgo para Chaitén: Sector norte es habitable. La Tercera Online, Chile. Recuperado de http://diario.latercera. com/2012/04/01/01/contenido/pais/31-1052419-definen-zonas-de-riesgo-para-chaiten-sector-norte-eshabitable.shtml

Beneton, R. (2006). Processos de Comunicação e Cultura Local: umestudo sobre a Rádio Paraitinga, de São
Luis do Paraitinga, SP. (Tesis de maestría inédita). Universidad de Sao Paulo: Brasil.

Berríos, M. (2009). La construcción de la vulnerabilidad social de la Colonia Arroyo del Maíz, Municipio de Poza Rica, Veracruz tras el proceso de reubicación por las inundaciones de 1999. (Tesis de titulación inédita). Universidad Nacional Autónoma de México.

Brennan, M. (2008). Conceptualizing resiliency: an interactional perspective for community and youth development. Child Care in Practice, 14(1), 55-64.

Brydon-Miller, M. Greenwood, D., \& Maguire, P. (2003). Why Action Research? Action Research, 1(1), 9-28.

Brzovic, D., Cornejo, R., González, J., Sánchez, R., \& Sobarzo, M. (2010). Que se derrumben los sentidos comunes y se reconstruyan las comunidades: Reflexiones a partir del terremoto y maremoto en Chile. Recuperado de http://www.opech.cl/editoriales/2010_03/ index_13_03_10_derrumben_sentidos_comunes.pdf

Cardona, O. (2001). La necesidad de repensar de manera holística los conceptos de vulnerabilidad y riesgo. Una crítica y una revisión necesaria para la gestión. Trabajo presentado en la International WorkConference on Vulnerability in Disaster Theory and Practice. Wageningen, Holanda.

Castro, J., \& Dingwell, D. (2009). Rapid ascent of rhyolitic magma at Chaitén volcano, Chile. Nature, 461, 780784.

Coloma, A. (2009). Una aproximación a la intervención del Trabajo Social Comunitario en situaciones de catástrofes y desastres. Cuadernos de Trabajo Social, 22, 243-257.

EERI (2010). The Mw 8.8. Chile Earthquake of February 27, 2010. Special Earthquake Report. Recuperado de http://www.eeri.org/site/images/eeri newsletter/2010_pdf/Chile10_insert.pdf

El País (2008). La erupción en Chile del Volcán Chaitén obliga a evacuar a casi 4.000 personas. El País, España. Recuperado de http://internacional. elpais.com/internacional/2008/05/03/ actualidad/1209765613_850215.html

EMOL (2011). Piñera oficializa refundación de Chaitén en sector norte de la ciudad, EMOL, Chile. Recuperado de http://www.emol.com/noticias/ nacional/2011/04/09/475139/pinera-oficializarefundacion-de-chaiten-en-sector-norte-de-la-ciudad. html

Espinoza, A. (2013). Aproximaciones a la comprensión de los efectos traumáticos del desplazamiento forzado producto de la erupción del Volcán Chaitén en la población 
retornada. P. Cabrera (Comp).Construcciones. Clínica de lo Traumático y Figurabilidad. Santiago: Editorial Universitaria.

Fals-Borda, O. (1985). Conocimiento y poder popular: Lecciones con campesinos en Nicaragua México y Colombia.Colombia: Siglo XXI Ediciones.

Feo, C., \& Feo, O. (2013). Impacto de los medios de comunicación en la salud pública. Saúdeem Debate, 37(96), 84-95.

Fernández, O. (2012). El lento retorno de los vecinos a Chaitén. La Tercera, Chile. Recuperado de http:// diario.latercera.com/2012/05/19/01/contenido/ pais/31-108816-9-el-lento--retorno--de-los-vecinos-achaiten.shtml

Flores, J. (2011). Psicología y praxis comunitaria. Una visión latinoamericana. México: Editorial Latinoamericana.

Freytes, A., \& Cross, C. (2011). Overcoming poor youth stigmatization and invisibility through art: A Participatory Action Research experience in Greater Buenos Aires. Action Research, 9(1), 65-82.

Gellert, G. (2012). El cambio de paradigma: de la atención de desastres a la gestión del riesgo. Boletín Científico Sapiens Research, 2(1), 13-17.

Gómez, A. (2010). El paisaje como patrimonio cultural, ambiental y productivo. Análisis e intervención para su sostenibilidad. Revista KEPES, 7(6), 91-106.

González, M. (2011). Estudio del impacto territorial-ambiental generado por la erupción del volcán Chaitén (Tesis de titulación inédita) Universidad de Chile: Chile.

Gutiérrez, N. (2008). "Operación rastrillo" de Carabineros logra evacuación total de Chaitén. EMOL, Chile. Recuperado de http://www.emol.com/noticias/ nacional/2008/05/08/303490/operacion-rastrillode-carabineros-logra-evacuacion-total-de-chaiten.html

Instituto Interamericano del Niño, Niña y Adolescente (2011). Derechos de la niñez y la adolescencia en la gestión de riesgo y desastres. Recuperado de http://www. resdal.org/facebook/Documento-Posicionamientospa.pdf

Jiménez, A. (2012). Los puntos cardinales de Chaitén. A propósito de la representación social del territorio. Recuperado de http://civdes.uchile.cl/wp-content/ uploads/2012/05/A.-Jimenez-Los-puntos-cardinalesde-Chait\%C3\%A9n.pdf

Krause, M. (2002). Investigación Acción Participativa: Una metodología para el desarrollo de autoayuda, participación y empoderamiento. En Durston, J. \& Miranda, F. (Eds.) Experiencias y metodología de la Investigación Participativa (pp. 41-56). Santiago:
Naciones Unidas Ediciones.

Larrañaga, O., \& Herrera, R. (2010). Encuesta Post Terremoto 2010: Principales resultados. Efectos en la calidad de vida de la población afectada por el terremoto/ tsunami. Ministerio de Planificación y PNUD, Santiago. http://www.redatam.org/chl/ ENCPT/documentos/ informe_encuesta_post_terremoto.pdf

Lara, L. (2009). The 2008 eruption of the Chaiten volcano, Chile: A preliminary report, Andean Geology, 36(1), 125-129.

Lavell, A. (1997). La prevención y mitigación de desastres urbanos: América Latina. En Lavell, A. (Ed.), Viviendo en Riesgo. Comunidades vulnerables y prevención de desastres en América Latina (pp. 149-169). Costa Rica: La RED Ediciones.

Londoño, D., \& Atehortúa, G. (2011). Los pasos en el camino de la sistematización. Revista Diálogos de Saberes, 1(2), 30-36.

Macaya, P. (2012). Volcán Chaitén: Consecuencias y discusiones. Recuperado de http://civdes.uchile. cl/wp-content/uploads/2012/08/Volc\%C3\%A1nChait\%C3\%A9n-consecuencias-y-discusiones.Macaya..pdf

Mardones, R. (2014). Sistematización de una experiencia de Investigación-Acción-Participativa para el fortalecimiento de la participación comunitaria de jóvenes en el Chaitén posterupción volcánica a través de la radio local (tesis de titulación inédita). Facultad de Ciencias Sociales, Universidad de Chile.

Mardones, R., Rueda, S., \& Guzmán, M. (2011). Tejiendo vínculos: una mirada a la organización "Renacer de Chaitén" de la tercera edad en un contexto de posdesastre. Cuadernos de Crisis y Emergencias, 10 (2).

Milan, S. (2006). Medios comunitarios y regulación. Una perspectiva de comunicación para el desarrollo. Investigación y Desarrollo, 14(2), 268-291.

MINVU (2010). Plan de Reconstrucción MINVU "Chile Unido Reconstruye Mejor". Ministerio de Vivienda y Urbanismo, Gobierno de Chile, $3^{\text {ra }}$ edición

Montero, M., \& Serrano-García, I. (2011). Una introducción a la Psicología Comunitaria en América Latina. En M. Montero \& I. Serrano-García (Eds.), Historias de la psicología comunitaria en América Latina: Participación y Transformación (pp. 23 -39). Buenos Aires: Editorial Paidós.

Montero, M. (2004). Introducción a la Psicología Comunitaria. Desarrollo, conceptos y procesos. Buenos Aires: Paidós. 
Montero, M. (2006). Hacer para transformar: El método en la Psicología Comunitaria. Buenos Aires: Paidós.

Montero, M. (2009). El fortalecimiento en la comunidad, sus dificultades y alcances. Universitas Psychologica, 8(3), 615-626.

Montero, M. (2010a). Crítica, autocrítica y construcción de teoría en la Psicología Social Latinoamericana. Revista Colombiana de Psicología, 19(2), 177-191.

Montero, M. (2010b). Fortalecimiento de la ciudadanía y transformación social: Área de encuentro entre la Psicología Política y la Psicología Comunitaria. Revista Psykhe, 19(2), 51-63.

Musitu, G., \& Buelga, S. (2004). Desarrollo Comunitario y Potenciación. En G. Musitu, J. Herrero, L. Cantera \& M. Montenegro (Eds.), Introducción a la Psicología Comunitaria, (pp. 167-195). Barcelona: UOC.

Ortiz, M., \& Borjas, B. (2008). La Investigación Acción Participativa: Aporte de Fals Borda a la educación popular. Espacio Abierto, 17(4), 615-627.

Osorio, J. (2008). Planificación e infraestructura en Chaitén. Recuperado de: http://www.digeo.cl/arch/img/ extension/seminario3/documentos/tema_6.pdf

Pérez-Sales, P. (2002). La concepción psicosocial y comunitaria del trabajo en catástrofes. Nuevas perspectivas en el marco de la elaboración de un programa internacional de formación de formadores. Cuadernos de Psiquiatría Comunitaria, 2(1), 6-17.

Pérez-Sales, P. (2004). Intervención en catástrofes desde un enfoque psicosocial y comunitario. Átopos, 1, 5-16.

Quiroz, R. (2006). Programa Puente. Un análisis desde el Enfoque Comunitario (Tesis de maestría inédita). Facultad de Ciencias Sociales, Universidad de Chile.

Ramírez, N. (2008). La anticampaña del "locutor rebelde" de Chaitén que se lanza a concejal. EMOL Online, Chile. Recuperado de http://www.emol.com/noticias/ nacional/2008/08/01/315511/la-anticampana-del- locutor-rebelde-de-chaiten-que-se-lanza-a-concejal.html Rebolledo, C. (2011). Comunicar el riesgo: Un desafío para la gestión pública. Gestión de comunicación pública del riesgo ante desastres naturales en la Secretaría Regional Ministerial de Salud de la Región del BíoBío (27 de febrero al 31 de diciembre de 2010) (Tesis de maestría inédita). Universidad de Concepción: Chile.

Rivera, M.; Velásquez, T., \& Morote, R. (2014). Participación y fortalecimiento comunitario en un contexto postterremoto en Chincha, Perú. Psicoperspectivas, 13(2), 144-155.

Rodríquez, J. (Ed.) (2009). Salud mental en la comunidad. Segunda Edición. Washington DC: OPS/OMS.

Todres, J. (2011). Mainstreaming children's rights in postdisaster settings. Emory International Law Review, 25, 1233-1261.

Ulivarri, P. (2010). La psicología comunitaria como posibilidad de transitar. Reflexiones desde la cotidianeidad. Revista Electrónica de Psicología Política, 8(22), 61-99.

Valenzuela, A. (2012). Análisis socioeconómico para la localidad de Chaitén después de la erupción del volcán homónimo y posterior aluvión del río Blanco (Tesis de grado inédita). Universidad Austral de Chile: Chile.

Vázquez, C. (2004). Refortalecimiento: un debate con el empowerment. Revista Interamericana de Psicología, $38,41-51$.

Vázquez, J. (2005). Investigación-Acción en derechos humanos: su representación social en el Movimiento Urbano Popular. Revista Polis, 1(2), 101-133.

Velásquez, F. (2012). CIVDES se adjudica Fondo Valentín Letelier. CIVDES, Chile. Recuperado de http://civdes. uchile.cl/?p=111

Villalobos, A. (2009). Intervención en crisis en situaciones de desastre: intervención de primera y de segunda instancia. Revista Médica de Costa Rica y Centroamérica, 66(587), 5-13. 